\title{
Significant association between clinical characteristics and changes in peripheral immuno-phenotype in large vessel vasculitis
}

Kotaro Matsumoto ${ }^{1}$, Katsuya Suzuki ${ }^{1}$, Keiko Yoshimoto ${ }^{1,2}$, Noriyasu Seki ${ }^{3}$, Hideto Tsujimoto ${ }^{3}$, Kenji Chiba ${ }^{3}$ and Tsutomu Takeuchi ${ }^{1 *}$ (D)

\begin{abstract}
Background: Large vessel vasculitis (LW) is a type of vasculitis characterized by granulomatous inflammation of medium- and large-sized arteries. Clinical assessment of acute phase reactants has been conventionally used to diagnose and monitor diseases; however, accurate assessment of vascular disease activity status can be difficult. In this study, we investigated comprehensive immuno-phenotyping to explore useful biomarkers associated with clinical characteristics.

Methods: Consecutive patients with newly diagnosed LW who visited our institution between May 2016 and May 2019 were enrolled. The number of circulating T cells, B cells, natural killer cells, dendritic cells, monocytes, and granulocytes was examined and chronologically followed. Baseline and time-course changes in immunophenotyping associated with disease activity were assessed.

Results: Comprehensive immuno-phenotyping data from 90 samples from each of 20 patients with LW were compared with those from healthy controls (HCs). The number of helper T (Th), follicular helper T (Tfh), $C D 8^{+} \mathrm{T}$, $\mathrm{CD} 14^{++} \mathrm{CD}_{16}{ }^{+}$monocytes, and neutrophils were higher in patients with giant cell arteritis (GCA) and/or Takayasu arteritis (TAK) than in HCs. Among them, the number of $\mathrm{CD}^{+} \mathrm{T}$ and $\mathrm{CD} 8^{+}$Tem were higher in patients with TAK than in GCA. Notably, memory $\mathrm{CD} 4^{+}$and $\mathrm{CD} 8^{+} \mathrm{T}$ cells in patients with TAK remained high even in the remission phase. Further analysis revealed that the number of Th1, Th17, and Tfh cells was associated with disease relapse in GCA and TAK and that the number of CD8 ${ }^{+}$T cells was associated with relapse in TAK. Th1, Th17, and Tfh cells decreased after treatment with biologic agents, while $C D 8^{+} \mathrm{T}$ cells did not.

Conclusions: Our results from peripheral immuno-phenotyping analysis indicate that the numbers of Th and Tfh cells changed along with the disease condition in both GCA and TAK, while that of CD8 ${ }^{+} T$ cells did not, especially in TAK. Treatment with biologic agents decreased the proportion of Th and Tfh cells, but not $\mathrm{CD}^{+} \mathrm{T}$ cells, in the patients. Chronological immuno-phenotyping data explained the difference in therapeutic response, such as reactivities against biologics, between GCA and TAK.
\end{abstract}

Keywords: Large vessel vasculitis, Giant cell arteritis, Takayasu arteritis, Immuno-phenotyping, Flow cytometry

\footnotetext{
* Correspondence: tsutake@z5.keio.jp

'Division of Rheumatology, Department of Internal Medicine, Keio University

School of Medicine, 35 Shinanomachi, Shinjuku-ku, Tokyo, Japan

Full list of author information is available at the end of the article
}

(c) The Author(s). 2019 Open Access This article is distributed under the terms of the Creative Commons Attribution 4.0 International License (http://creativecommons.org/licenses/by/4.0/), which permits unrestricted use, distribution, and reproduction in any medium, provided you give appropriate credit to the original author(s) and the source, provide a link to the Creative Commons license, and indicate if changes were made. The Creative Commons Public Domain Dedication waiver (http://creativecommons.org/publicdomain/zero/1.0/) applies to the data made available in this article, unless otherwise stated. 


\section{Background}

Large vessel vasculitis (LVV) is a type of vasculitis characterized by granulomatous inflammation of mediumand large-sized arteries [1-3]. According to the Chapel Hill Consensus Conference 2012 definition [4], giant cell arteritis (GCA) and Takayasu arteritis (TAK) constitute different types of primary LVV.

Recent clinical trials for LVV with tocilizumab (TCZ) have revealed that therapies targeting interleukin (IL)-6 are effective for reducing relapse and glucocorticoid (GC) dose in patients [5-7]. Also, tumor necrosis factor (TNF)$\alpha$ inhibition therapies such as infliximab (IFX), etanercept, and adalimumab is effective for TAK $[8,9]$, and $\mathrm{T}$ lymphocyte-targeted therapy represented by abatacept is effective for GCA [10]. While targeted therapies have been successful, a complete picture of how immune cell profiles reflect the pathophysiology of LVV is currently lacking. In particular, differences in the baseline immunological profile between GCA and TAK and changes during treatment with GC and/or biologics are not well described.

LVV are intractable rare disease entities with a high relapse rate. Disease progression in asymptomatic patients is an important issue in the clinical management of LVV. There is a strong expectation that useful biomarkers may be present in the peripheral blood. We therefore aimed to identify the immunological characteristics of LVV and their clinical significance by comprehensively examining the immuno-phenotypes of LVV patients.

\section{Patients and methods}

\section{Patients and healthy controls}

Patients with newly diagnosed LVV who visited Keio University Hospital and fulfilled the American College of Rheumatology criteria for GCA [11] and TAK [12] between May 2016 and May 2019 were consecutively enrolled. Patients with secondary LVV that could mimic GCA/TAK (for example, Cogan syndrome, sarcoidosis, Kawasaki disease, Behçet disease, IgG4-related disease, syphilis, tuberculosis, Ehlers-Danlos syndrome, Marfan syndrome, and neurofibromatosis) were excluded based on the medical chart at screening. We confirmed that the healthy controls (HCs) did not have an autoimmune disease, severe allergic disorder, malignancy, or infection.

This study was approved by the research ethics committee of the Keio University School of Medicine (\#20140335) and was conducted according to the Declaration of Helsinki. Informed consent was obtained from all patients and HCs.

\section{Clinical assessment}

Clinical information was obtained from patients' records. We collected information on age; gender; time from symptom onset to diagnosis; body mass index at diagnosis; smoking habit; comorbidities, including hypertension, diabetes mellitus, dyslipidemia, chronic kidney disease, polymyalgia rheumatica (PMR) [13], and inflammatory bowel disease (IBD) [14]; laboratory data on erythrocyte sedimentation rate (ESR) and C-reactive protein (CRP) levels at diagnosis and each visit; and treatment during followup. Arterial involvement was evaluated using histological and/or radiological examinations (any or all of ultrasonography, computed tomography $(\mathrm{CT})$, magnetic resonance imaging, and positron emission tomography CT).

Achievement of remission was defined as the disappearance of clinical symptoms with normal CRP with prednisolone $(\mathrm{PSL})<10 \mathrm{mg} /$ day [5-10]. Relapse was defined as the reappearance of vasculitis-related manifestations accompanied by elevated levels of acute phase reactants requiring an increase in GC dose or additional immunosuppressive agents [5-10].

\section{FACS analysis}

We collected clinical data and peripheral blood samples from patients with GCA and TAK at the time of diagnosis (week 0 ) and subsequently at weeks 4, 12, 24, and 52 of treatment. Twenty microliters of heparinized blood samples was collected from patients with LVV (GCA, $n=12$; TAK, $n=8$ ), and FACS analysis for immuno-phenotyping was carried out without delay after collecting the samples. FACS and data analyses were conducted on a FACS Aria II (BD Biosciences) and using FlowJo v.7.6.4 Software (Tree Star, Stanford University, CA, USA), according to the methods recommended by the manufacturers of the antibodies used (BD Biosciences and BioLegend: Additional file 4: Table S1). The phenotypes of immune cell subsets were defined based on the Human Immunology Project protocol [15]. Micro-sized cells, such as fragments of dead cells, were gated out when we analyzed the cells. Details of the gating strategy are shown in Additional file 4: Table S2 and Additional file 1: Figure S1. The mean number of each immune cell phenotype from patients with GCA and TAK was compared with that from age-matched HCs, and the fold change was calculated by dividing the cell number from patients by the corresponding average cell number from HCs. Fold change values for each immune cell phenotype were then compared between the groups.

Baseline data was analyzed using one-way analysis of variance (ANOVA) and post hoc test. Then, chronological data was analyzed using correlation analysis to identify the immune cell subsets associated with disease relapse. We also examined whether the use of biologic agents reduced the immune cells associated with disease relapse.

\section{Statistical analysis}

Descriptive statistics were used to summarize the data. Continuous variables are shown as median and IQR. 
Baseline immuno-phenotyping data were analyzed by one-way ANOVA and post hoc test using the TukeyKramer test. The difference between pre- and posttreatment data was assessed using the Wilcoxon signedrank test. The correlation coefficient was used for matrix correlation analysis. $p$ values less than 0.05 were considered significant. All analyses were conducted using JMP version 14.0 (SAS Institute, Cary, NC, USA) or GraphPad Prism software V.8.0 (GraphPad, La Jolla, CA, USA).

\section{Results}

\section{Baseline clinical characteristics and therapeutic response in LVV patients}

We collected FACS data and clinical profiles from 20 Japanese LVV patients who were followed longitudinally across a total of 90 visits. None of the patients had been previously treated with $\mathrm{GC}$ or any biologic agent. All patients received GC therapy at an initial dose equivalent to $0.6-1.0 \mathrm{mg} \mathrm{PSL} / \mathrm{kg} /$ day, which was tapered by the attending physician based on previously reported clinical trials [5-10].

We evaluated the patients at each visit based on their symptoms, ESR, CRP, and PSL dose. Baseline characteristics, treatment, and effects of treatment in patients with LVV and HCs are summarized in Table 1. TAK was younger (GCA vs TAK, 71 vs 47 years), and the time from onset to diagnosis was longer compared with GCA (2.5 vs 3.6 months). Fifty percent (6/12) of GCA were with PMR, and $25 \%(2 / 8)$ of TAK were with IBD. Laboratory tests of ESR and CRP were not different. The proportion of relapse and/or surgery was higher in TAK than in GCA $(33 \%[4 / 12]$ vs $63 \%$ [5/8]).

\section{Baseline peripheral immune cell phenotypes in LVV patients}

We compared the absolute number of circulating immune cells among GCA, TAK, and HCs using one-way ANOVA and post hoc test. We revealed that the

Table 1 Clinical characteristics of patients with LW

\begin{tabular}{|c|c|c|c|c|}
\hline Variable & GCA, $n=12$ & $\mathrm{TAK}, n=8$ & HC for GCA, $n=5$ & $\mathrm{HC}$ for $\mathrm{TAK}, n=5$ \\
\hline \multicolumn{5}{|l|}{ Baseline demographic } \\
\hline Age at diagnosis, years (IQR) & $71(69-77)$ & $47(32-56)$ & $72(61-78)$ & $50(28-58)$ \\
\hline Male, $n(\%)$ & $7(58)$ & $4(50)$ & $2(40)$ & $1(20)$ \\
\hline Time from symptom onset to diagnosis, months (IQR) & $2.5(1.2-4.8)$ & $3.6(2.7-12)$ & & \\
\hline Body mass index at diagnosis, $\mathrm{kg} / \mathrm{m}^{2}$ (IQR) & $18(17-22)$ & $23(17-24)$ & & \\
\hline Smoking, $n(\%)$ & $6(50)$ & $3(38)$ & & \\
\hline \multicolumn{5}{|l|}{ Comorbidities } \\
\hline Hypertension, $n(\%)$ & $4(33)$ & $1(13)$ & & \\
\hline Diabetes mellitus, $n(\%)$ & $2(17)$ & $0(0)$ & & \\
\hline Dyslipidemia, $n(\%)$ & $5(42)$ & $1(13)$ & & \\
\hline Chronic kidney disease, $n$ (\%) & $1(8.3)$ & $2(25)$ & & \\
\hline PMR, $n(\%)$ & $6(50)$ & $0(0)$ & & \\
\hline $\mathrm{IBD}, n(\%)$ & $0(0)$ & $2(25)$ & & \\
\hline \multicolumn{5}{|l|}{ Laboratory tests } \\
\hline $\mathrm{ESR}, \mathrm{mm} / \mathrm{h}(\mathrm{IQR})$ & $120(115-134)$ & $70(56-109)$ & & \\
\hline CRP, mg/dL (IQR) & $4.6(2.2-8.2)$ & $4.8(2.1-7.9)$ & & \\
\hline \multicolumn{5}{|l|}{ Arterial involvement } \\
\hline GCA: cranial/LV, $n$ & $8 / 4$ & - & & \\
\hline TAK: type I/Ila/Ilb/II/IVN, n & - & $1 / 1 / 1 / 1 / 0 / 4$ & & \\
\hline \multicolumn{5}{|l|}{ Induction treatment } \\
\hline Initial dose of PSL, mg (IQR) & $50(40-59)$ & $60(50-60)$ & & \\
\hline Biologic agents, $n(\%)$ & TCZ: 5 (42) & TCZ, 4 (50); IFX, 2 (25) (25) & & \\
\hline Relapse, $n(\%)$ & $4(33)$ & $3(38)$ & & \\
\hline Surgery, $n(\%)$ & $0(0)$ & $3(38)$ & & \\
\hline Relapse/surgery, $n(\%)$ & $4(33)$ & $5(63)$ & & \\
\hline Time to first relapse/surgery, months (IQR) & $6.0 \pm 4.0$ & $3.6 \pm 2.2$ & & \\
\hline
\end{tabular}

LVV large vessel vasculitis, GCA giant cell arteritis, TAK Takayasu arteritis, $H C$ healthy control, PMR polymyalgia rheumatica, IBD inflammatory bowel syndrome, ESR erythrocyte sedimentation rate, CRP C-reactive protein, LV large vessel, PSL prednisolone 
number of helper $\mathrm{T}(\mathrm{Th})$, follicular helper $\mathrm{T}$ (Tfh), $\mathrm{CD} 8^{+}$ $\mathrm{T}, \mathrm{CD}^{+}{ }^{+} \mathrm{Tem}, \mathrm{CD} 14^{++} \mathrm{CD} 6^{+}$monocytes, and neutrophils was higher in patients with GCA and/or TAK than $\mathrm{HCs}$. Among them, the number of $\mathrm{CD}^{+} \mathrm{T}$ and $\mathrm{CD} 8^{+}$ Tem was higher in patients with TAK than GCA (Table 2).

Fold change in the number of immune cells in patients with GCA and TAK was determined by dividing the cell number in patients by the average cell number of the corresponding immuno-phenotype in age-matched HCs (Fig. 1). Then, fold changes of each cell subset in patients with GCA or TAK, GCA with or without PMR, and TAK with or without IBD were compared. The proportion of $\mathrm{Tfh}$, Tfh $1, \mathrm{Tfh} 17, \mathrm{CD}^{+} \mathrm{T}$, naive $\mathrm{CD}^{+} \mathrm{T}$, $\mathrm{CD}^{+}$Tem, CD19 ${ }^{+} \mathrm{B}, \mathrm{CD}_{2} 7^{-} \mathrm{IgD}^{+}$naive $\mathrm{B}$, and $\mathrm{CD} 27^{+}$ $\mathrm{IgD}^{-}$memory $\mathrm{B}$ was higher in TAK than in GCA, which was consistent with ANOVA (Fig. 1a). There was no statistical difference in the proportion of cell subsets between patients with or without PMR/IBD (Fig. 1b, c).

\section{Chronological changes in immuno-phenotype associated in LVV without relapse}

Because of the higher proportion of relapse/surgery in patients with TAK than GCA $[3,16,17]$, we hypothesized that the immuno-phenotype profile may differ after treatment between the two groups of the patients. Thus, we compared the immuno-phenotyping data between GCA $(n=8)$ and TAK $(n=5)$ patients without relapse. Compared to patients with GCA (Fig. 2a), memory $\mathrm{CD}^{+} \mathrm{T}$ and $\mathrm{CD}^{+} \mathrm{T}$ cells in patients with TAK remained high even in the remission phase (Fig. 2b). To assess the effect of treatments, we analyzed the fold changes in immune cell subsets in patients successfully treated with GC and biologic agents (GCA, $n=5$; TAK, $n=3$ ). As a result, we found that memory $\mathrm{CD} 4^{+} \mathrm{T}$ and $\mathrm{CD}^{+} \mathrm{T}$ cells in patients with TAK also remained high levels even after treatment with biologic agents (Additional file 2: Figure S2A and S2B).

\section{Chronological changes in immuno-phenotype associated with disease relapse}

To assess changes in immuno-phenotype at relapse, we longitudinally profiled the immuno-phenotyping data of patients who achieved remission then relapsed. We followed the immuno-phenotyping data of seven patients (GCA, $n=4$; TAK, $n=3$ ) who achieved remission then relapsed until week 52 of treatment and calculated the correlation between the fluctuation in each immune cell subset and change in disease activity.

The results of matrix correlation analysis for each subset and the fluctuation in disease activity are shown in Additional file 3: Figure S3. Given that Th1 and Th17 have been implicated in the pathogenesis of GCA and TAK [18-20], we examined the changes in relevant selected subsets including Th1, Th17, Tfh, $\mathrm{CD}^{+} \mathrm{T}$, and CD19 ${ }^{+} \mathrm{B}$ cells and laboratory data of ESR and CRP (Fig. 3). Th1, Th17, and Tfh cells were strongly correlated with disease activity in GCA and TAK (Fig. 3A), as well as ESR and CRP levels (Fig. 3B). Notably, $\mathrm{CD}^{+} \mathrm{T}$ cells were strongly correlated with disease activity in TAK, but not in GCA. In addition, the fold changes of $\mathrm{CD}^{+} \mathrm{T}$ cells at onset (TAK vs GCA, $1.9 \pm 0.8$ vs $0.3 \pm$ $0.3, p=0.032)$ and at relapse $(2.0 \pm 0.9$ vs $0.4 \pm 0.1, p=$ $0.011)$ were significantly higher in patients with TAK than those in GCA.

\section{Chronological changes in immuno-phenotype associated with treatment with biologics}

Eleven patients (GCA, $n=5$; TAK: $n=6$ ) were treated with TCZ $(n=9)$ and IFX $(n=2)$. To determine whether these drugs cause immunological changes, we compared the number of immune cells of selected subsets before and after treatment with biologic agents (Fig. 4). It is noteworthy that treatment with biologic agents did not decrease the proportion of $\mathrm{CD}^{+} \mathrm{T}$ cells (Fig. 4d), while the treatment decreased the proportion of Th1, Th17, and Tfh cells (Fig. $4 \mathrm{a}-\mathrm{c}$ ).

\section{Discussion}

This study examined the baseline and chronological changes in immuno-phenotype profiles in patients with LVV. We identified the common characteristics and differences in immuno-phenotypes between patients with GCA and TAK. $\mathrm{CD}^{+} \mathrm{T}$ and $\mathrm{CD} 8^{+}$Tem were higher in TAK patients than in GCA or HCs. Further study using matrix correlation analysis revealed that Th1, Th17, Tfh, and $\mathrm{CD}^{+} \mathrm{T}$ cells were associated with disease relapse in TAK. Changes in these immune cells were useful for distinguishing active LVV from remission. We also revealed that treatment with biologic agents decreased the number of Th1, Th17, and Tfh cells, suggesting that suppression of these immune cells may be responsible for the drugs' therapeutic effects.

Compared to the immuno-phenotypes in $\mathrm{HCs}$, the number of Th, Tfh, $\mathrm{CD} 8^{+} \mathrm{T}, \mathrm{CD} 14^{++} \mathrm{CD} 16^{+}$intermediate monocytes, and neutrophils were elevated in patients with GCA and/or TAK. A recent report by our group also found that similar subsets of immune cells were elevated in patients with anti-neutrophil cytoplasmic antibody-associated vasculitis [21]. $\mathrm{CD}^{++} 4^{++} \mathrm{CD} 16^{+}$ monocytes and neutrophils may be involved in a common pathway with important roles in small to large vessel vasculitis. Tertiary lymphoid organs are typically identified using arterial histological examination [22], which may explain the increase in Th and Tfh cells in LVV patients.

Comparison of immuno-phenotypes in patients with GCA and TAK demonstrated that the number of $\mathrm{CD} 8^{+}$ 
Table 2 Comparison of peripheral immune cells among GCA, TAK, and HCs

\begin{tabular}{|c|c|c|c|c|c|c|c|c|}
\hline \multirow{2}{*}{$\begin{array}{l}\text { Immune cell subtype } \\
\text { (cells per } \mu \mathrm{L} \text { ) }\end{array}$} & \multirow[t]{2}{*}{ GCA, $n=12$} & \multirow[t]{2}{*}{ TAK, $n=8$} & \multirow{2}{*}{$\begin{array}{l}\text { HC for } \\
\text { GCA, } n=5\end{array}$} & \multirow{2}{*}{$\begin{array}{l}\text { HC for } \\
\text { TAK, } n=5\end{array}$} & \multicolumn{2}{|l|}{ ANOVA } & \multicolumn{2}{|c|}{ Post hoc test } \\
\hline & & & & & $p$ value & GCA vs TAK & GCA vs HC & TAK vs HC \\
\hline$\overline{\mathrm{CD}^{+}{ }^{+} \mathrm{T}}$ & $491 \pm 207$ & $621 \pm 282$ & $512 \pm 203$ & $383 \pm 231$ & 0.36 & & & \\
\hline CD4 HLA-DR ${ }^{+}$ & $16 \pm 8.9$ & $11 \pm 3.2$ & $8.5 \pm 0.80$ & $7.6 \pm 5.1$ & 0.074 & & & \\
\hline CD4 naive & $214 \pm 38$ & $248 \pm 47$ & $270 \pm 66$ & $210 \pm 59$ & 0.85 & & & \\
\hline CD4 Teff & $5.1 \pm 4.5$ & $26 \pm 53$ & $5.4 \pm 3.2$ & $18 \pm 21$ & 0.46 & & & \\
\hline CD4 Tcm & $194 \pm 96$ & $220 \pm 90$ & $143 \pm 33$ & $121 \pm 71$ & 0.18 & & & \\
\hline CD4 Tem & $78 \pm 49$ & $128 \pm 83$ & $66 \pm 1.0$ & $77 \pm 29$ & 0.18 & & & \\
\hline Th1 & $80 \pm 42$ & $114 \pm 18$ & $62 \pm 6.1$ & $62 \pm 30$ & 0.23 & & & \\
\hline Th1 HLA-DR ${ }^{+}$ & $25 \pm 14$ & $18 \pm 19$ & $9.3 \pm 3.1$ & $13 \pm 11$ & 0.22 & & & \\
\hline Th2 & $40 \pm 20$ & $28 \pm 18$ & $20 \pm 9.7$ & $19 \pm 18$ & 0.10 & & & \\
\hline Th2 HLA-DR ${ }^{+}$ & $6.4 \pm 1.6$ & $3.0 \pm 2.2$ & $2.1 \pm 1.0$ & $3.1 \pm 1.9$ & 0.13 & & & \\
\hline Th17 & $57 \pm 38$ & $78 \pm 33$ & $36 \pm 14$ & $31 \pm 14$ & 0.061 & & & \\
\hline Th17 HLA-DR ${ }^{+}$ & $9.9 \pm 8.5$ & $10 \pm 5.0$ & $4.0 \pm 1.9$ & $5.1 \pm 4.1$ & 0.26 & & & \\
\hline Treg & $20 \pm 12$ & $25 \pm 16$ & $11 \pm 5.9$ & $12 \pm 5.3$ & 0.16 & & & \\
\hline Treg HLA-DR ${ }^{+}$ & $8.9 \pm 7.2$ & $7.8 \pm 4.2$ & $5.0 \pm 1.0$ & $3.1 \pm 1.5$ & 0.20 & & & \\
\hline Tfh & $68 \pm 29$ & $87 \pm 31$ & $63 \pm 20$ & $36 \pm 21$ & 0.025 & 0.43 & 0.98 & 0.014 \\
\hline Tfh1 & $16 \pm 8.8$ & $25 \pm 3.3$ & $15 \pm 0.9$ & $11 \pm 4.9$ & 0.063 & & & \\
\hline Tfh2 & $8.3 \pm 5.0$ & $9.1 \pm 8.8$ & $4.1 \pm 1.1$ & $5.2 \pm 3.6$ & 0.41 & & & \\
\hline Tfh17 & $24 \pm 11$ & $29 \pm 9.8$ & $23 \pm 10$ & $10 \pm 7.6$ & 0.035 & 0.21 & 0.99 & 0.057 \\
\hline Tfr & $5.1 \pm 2.5$ & $5.6 \pm 3.5$ & $3.7 \pm 0.14$ & $2.6 \pm 2.6$ & 0.23 & & & \\
\hline $\mathrm{CD}^{+} \mathrm{T}$ & $189 \pm 115$ & $331 \pm 128$ & $228 \pm 126$ & $163 \pm 52$ & 0.039 & 0.044 & 0.93 & 0.033 \\
\hline CD8 HLA-DR ${ }^{+}$ & $24 \pm 22$ & $16 \pm 9.6$ & $5.6 \pm 2.6$ & $6.6 \pm 4.1$ & 0.12 & & & \\
\hline CD8 naive & $23 \pm 17$ & $77 \pm 50$ & $94 \pm 61$ & $74 \pm 19$ & 0.015 & 0.054 & 0.043 & 0.99 \\
\hline CD8 Teff & $90 \pm 89$ & $98 \pm 52$ & $30 \pm 12$ & $43 \pm 23$ & 0.24 & & & \\
\hline CD8 Tcm & $20 \pm 13$ & $28 \pm 21$ & $9.9 \pm 4.6$ & $12 \pm 6.6$ & 0.15 & & & \\
\hline CD8 Tem & $57 \pm 35$ & $128 \pm 87$ & $54 \pm 23$ & $51 \pm 15$ & 0.024 & 0.028 & 0.99 & 0.033 \\
\hline$\gamma \delta T$ & $5.5 \pm 5.1$ & $22 \pm 26$ & $4.7 \pm 1.7$ & $18 \pm 32$ & 0.22 & & & \\
\hline NKT & $29 \pm 33$ & $43 \pm 34$ & $3.7 \pm 0.7$ & $29 \pm 13$ & 0.22 & & & \\
\hline $\mathrm{CD} 19^{+} \mathrm{B}$ & $97 \pm 51$ & $211 \pm 175$ & $226 \pm 89$ & $94 \pm 42$ & 0.045 & 0.11 & 0.17 & 0.23 \\
\hline $\mathrm{CD}_{27^{-}}$IgD ${ }^{+}$naive $\mathrm{B}$ & $79 \pm 48$ & $161 \pm 151$ & $186 \pm 77$ & $52 \pm 13$ & 0.052 & & & \\
\hline $\mathrm{CD}_{27^{-}}$IgD $^{+}$activated $\mathrm{B}$ & $2.4 \pm 1.6$ & $6.7 \pm 5.3$ & $13 \pm 4.8$ & $13 \pm 11$ & 0.0038 & 0.35 & 0.017 & 0.29 \\
\hline $\mathrm{CD}_{27^{+}} \mathrm{lgD}-$ memory B & $11 \pm 5.8$ & $31 \pm 20$ & $18 \pm 3.9$ & $16 \pm 12$ & 0.015 & 0.0086 & 0.74 & 0.17 \\
\hline Plasmablast & $0.6 \pm 0.8$ & $3.3 \pm 5.3$ & $0.2 \pm 0.06$ & $0.9 \pm 1.0$ & 0.17 & & & \\
\hline Plasma cell & $0.5 \pm 0.5$ & $2.1 \pm 3.4$ & $0.05 \pm 0.0$ & $0.3 \pm 0.4$ & 0.17 & & & \\
\hline NK & $171 \pm 170$ & $149 \pm 77$ & $123 \pm 6.4$ & $153 \pm 48$ & 0.92 & & & \\
\hline DC & $14 \pm 9.7$ & $17 \pm 14$ & $21 \pm 3.7$ & $19 \pm 15$ & 0.72 & & & \\
\hline $\mathrm{mDC}$ & $8.2 \pm 5.8$ & $6.6 \pm 2.3$ & $15 \pm 1.4$ & $11 \pm 5.4$ & 0.035 & 0.88 & 0.071 & 0.43 \\
\hline $\mathrm{pDC}$ & $1.3 \pm 1.0$ & $2.2 \pm 1.4$ & $3.2 \pm 1.7$ & $4.5 \pm 6.4$ & 0.20 & & & \\
\hline Monocyte & $209 \pm 91$ & $258 \pm 30$ & $93 \pm 43$ & $158 \pm 38$ & 0.024 & 0.59 & 0.11 & 0.020 \\
\hline $\mathrm{CD} 14^{++} \mathrm{CD} 16^{-}$ & $144 \pm 73$ & $188 \pm 94$ & $80 \pm 4.3$ & $116 \pm 35$ & 0.096 & & & \\
\hline $\mathrm{CD} 14^{++} \mathrm{CD}_{16}^{+}$ & $48 \pm 36$ & $44 \pm 22$ & $5.3 \pm 0.5$ & $20 \pm 15$ & 0.040 & 0.98 & 0.049 & 0.30 \\
\hline $\mathrm{CD} 14^{+} \mathrm{CD} 16^{+}$ & $11 \pm 7.0$ & $16 \pm 7.3$ & $4.5 \pm 3.5$ & $12 \pm 3.1$ & 0.084 & & & \\
\hline Eosinophil & $76 \pm 36$ & $135 \pm 115$ & $50 \pm 40$ & $63 \pm 45$ & 0.14 & & & \\
\hline Neutrophil & $4009 \pm 2054$ & $4329 \pm 2425$ & $1232 \pm 688$ & $1551 \pm 759$ & 0.013 & 0.98 & 0.073 & 0.036 \\
\hline
\end{tabular}


Table 2 Comparison of peripheral immune cells among GCA, TAK, and HCs (Continued)

\begin{tabular}{|c|c|c|c|c|c|c|c|c|}
\hline \multirow{2}{*}{$\begin{array}{l}\text { Immune cell subtype } \\
\text { (cells per } \mu \mathrm{L} \text { ) }\end{array}$} & \multirow[t]{2}{*}{$\mathrm{GCA}, n=12$} & \multirow[t]{2}{*}{ TAK, $n=8$} & \multirow{2}{*}{$\begin{array}{l}\text { HC for } \\
\text { GCA, } n=5\end{array}$} & \multirow{2}{*}{$\begin{array}{l}\text { HC for } \\
\text { TAK, } n=5\end{array}$} & \multicolumn{2}{|l|}{ ANOVA } & \multicolumn{2}{|c|}{ Post hoc test } \\
\hline & & & & & $\overline{p \text { value }}$ & GCA vs TAK & $\overline{\mathrm{GCA} \text { vs HC}}$ & TAK vs HC \\
\hline Basophil & $30 \pm 25$ & $35 \pm 14$ & $30 \pm 0.1$ & $26 \pm 26$ & 0.90 & & & \\
\hline
\end{tabular}

Comparison between of baseline peripheral immune cell number between GCA $(n=12)$, TAK $(n=8)$, HC for GCA $(n=5)$, and HC for TAK $(n=5)$ using ANOVA and post hoc test

Th helper T, Tfh follicular helper T, NK natural killer, $D C$ dendritic cell, $m D C$ myeloid $D C, p D C$ plasmacytoid $D C$

$\mathrm{T}$ cells at onset and at relapse was higher in patients with TAK than in those with GCA. TAK is associated with major histocompatibility (MHC) class I alleles, human leukocyte antigen (HLA)-A24 and B52 [23, 24], while GCA is associated with MHC class II alleles, HLA-
DR4 $[25,26]$, suggesting that TAK may be associated with activation of $\mathrm{CD} 8^{+} \mathrm{T}$ cells. Additionally, a comparison between remission and non-remission phases showed that the proportion of immune cells of several subsets remained elevated in TAK patients who had

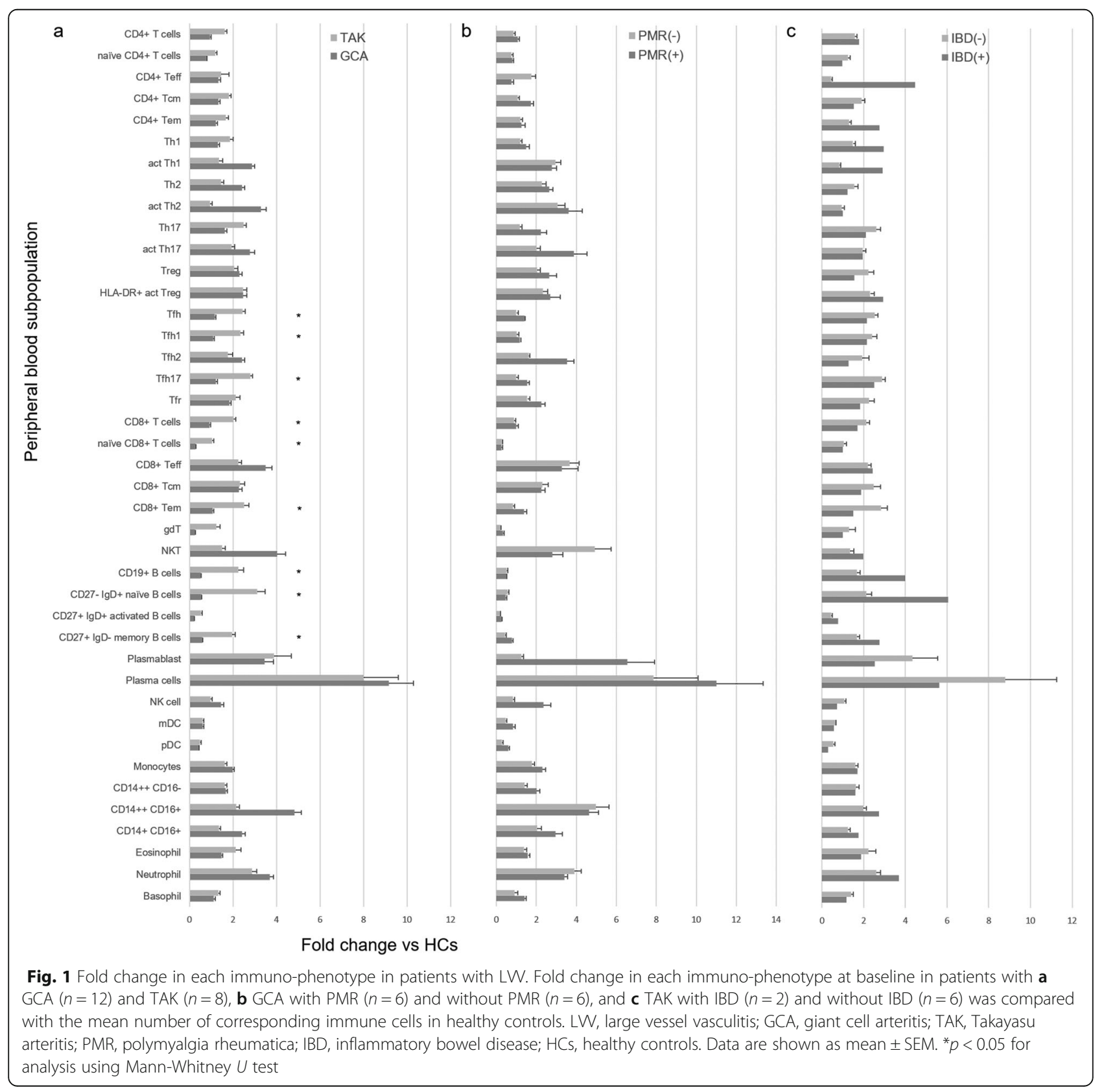



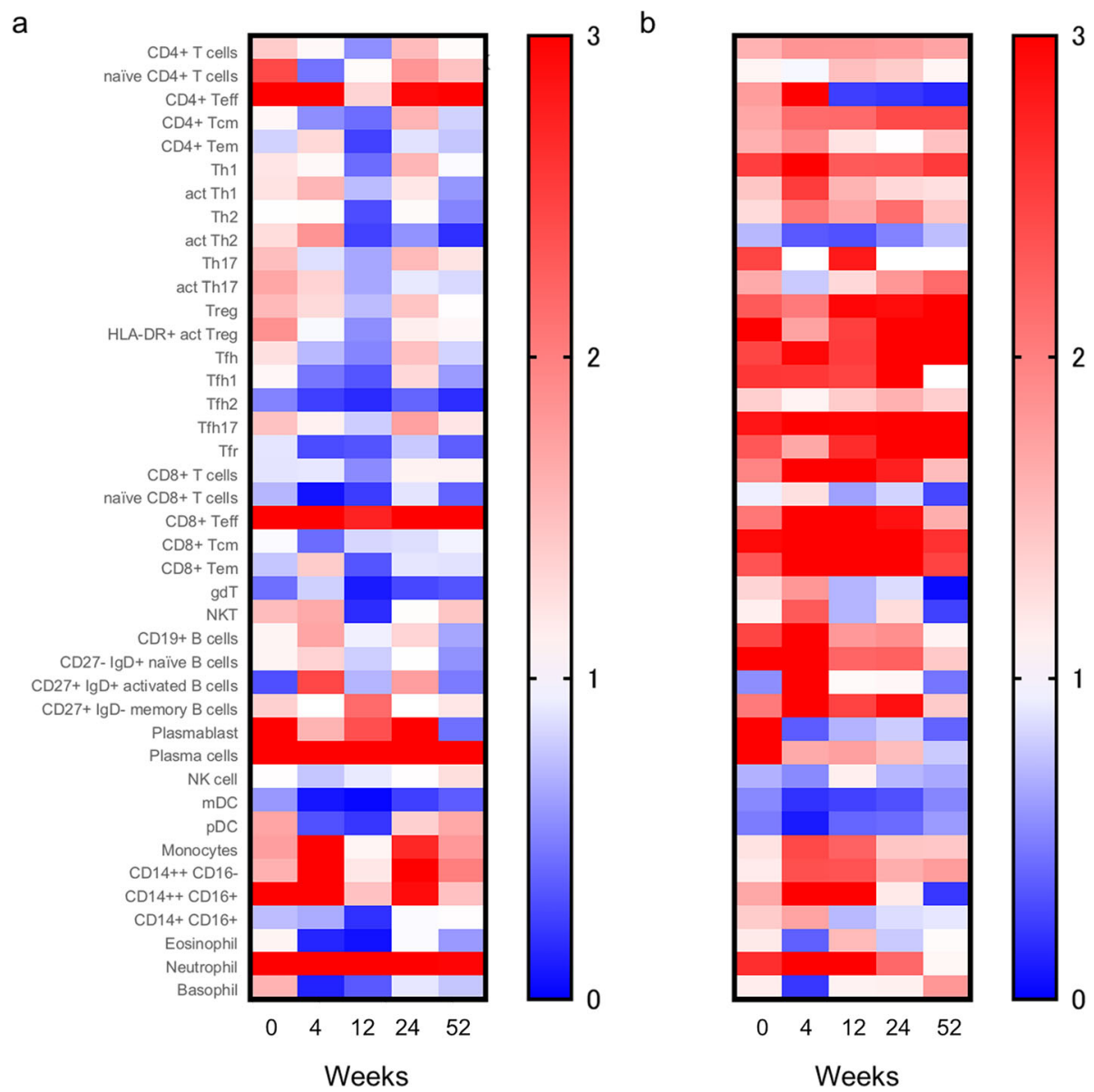

Fig. 2 Heatmap of baseline and time-course immuno-phenotyping in each subset in LW patients without relapse. Fold change in each immunophenotype at baseline and at weeks $4,12,24$, and 52 of treatment in a GCA $(n=8)$ and $\mathbf{b}$ TAK $(n=5)$ patients without relapse. LW, large vessel vasculitis; GCA, giant cell arteritis; TAK, Takayasu arteritis

achieved remission, suggesting that conventional clinical assessments to evaluate disease activity in TAK are limited. Despite considerable discussion on the potential differences between GCA and TAK [3, 16-20, 27], the immunological difference remains unknown. The higher relapse rate in patients with TAK compared to those with GCA during treatment is consistent with our finding that immune cell involvement is persistently present in patients with TAK.

GC is the mainstay of treatment for LVV, while conventional immunosuppressants have modest GC-sparing effects. Recent studies have shown that biological drugs may be a valid therapeutic option, especially in patients with severe and/or relapsing LVV. A previous report showed that regulatory $\mathrm{T}$ cells are increased after treatment with TCZ [28]. Despite this, we do not currently have a complete picture of how immune cell profiles reflect treatment with biologic agents. We found that the number of Th1, Th17, Tfh, and $\mathrm{CD}^{+} \mathrm{T}$ cells was correlated with disease activity and may therefore be useful alternative biomarkers for evaluating disease status. TCZ and IFX decreased the number of Th1, Th17, and Tfh cells, suggesting that these biologic agents exert their effects by regulating the function of these pathogenic immune cells. In contrast, neither TCZ nor IFX suppressed $\mathrm{CD}^{+} \mathrm{T}$ cells, which may play an important role in the pathogenesis of TAK. New treatments targeting $\mathrm{CD}^{+} \mathrm{T}$ cells are needed.

Our study has several limitations. First, this is a study with a small sample size and with a short observation period. Second, we did not investigate the types of immune cells that infiltrated the affected tissues. Further analysis with a large cohort may be required to clarify the responsible cell subsets of the pathogenesis of LVV.

Allowing for these limitations, this is the first study to comprehensively demonstrate the peripheral immunophenotype profile of LVV. We demonstrated the differences of the baseline and time-course immunophenotype profiles between GCA and TAK. 


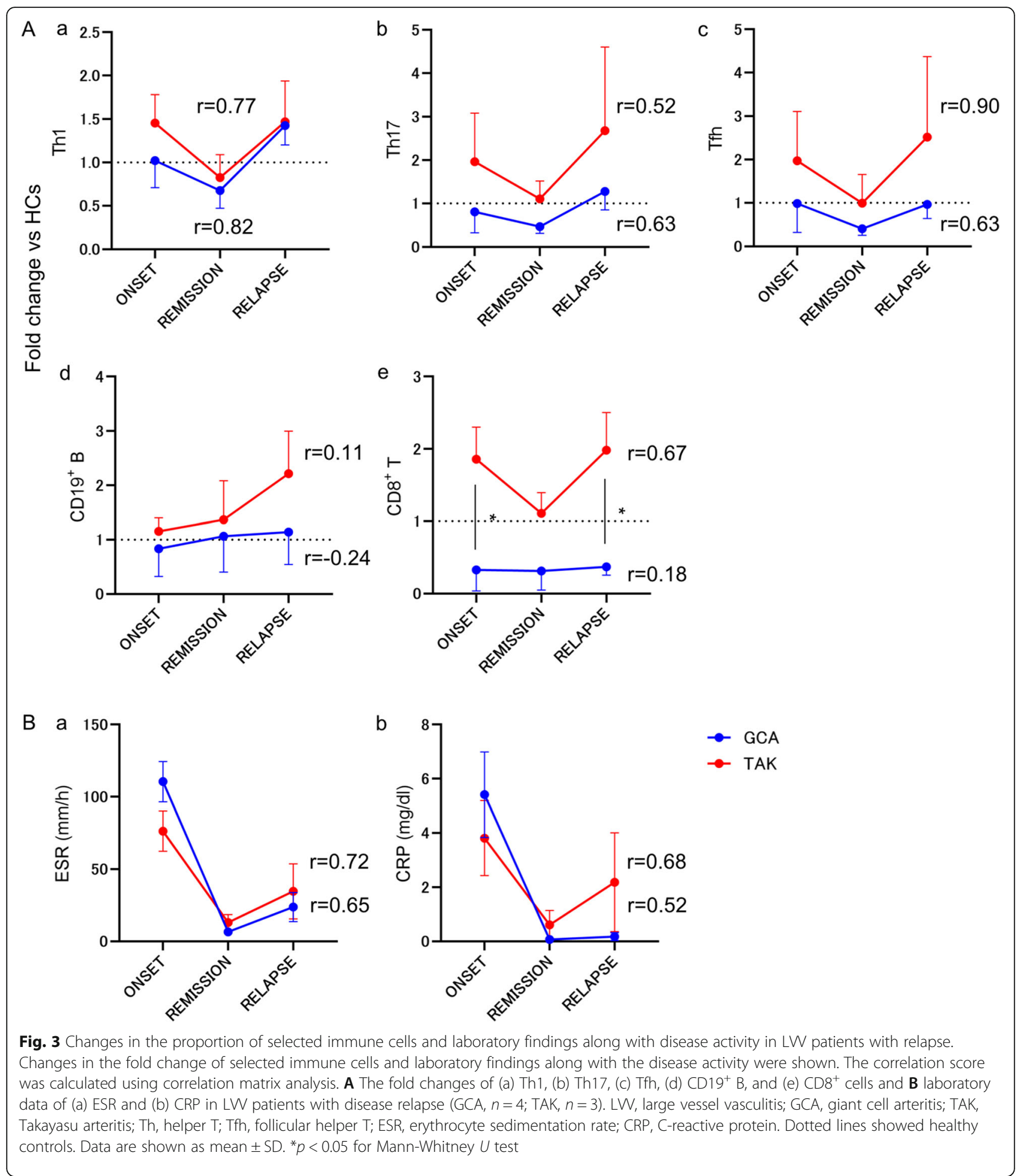

\section{Conclusions}

Our results from peripheral immuno-phenotyping analysis indicate that the numbers of Th and Tfh cells changed along with the disease condition in both GCA and TAK, while that of $\mathrm{CD}^{+} \mathrm{T}$ cells did not, especially in TAK.
Chronological immuno-phenotyping data explained the difference in therapeutic response, such as reactivities against biologics, between GCA and TAK. Accumulation of further evidence on immuno-phenotype profiles is expected to improve treatment options for LVV patients. 

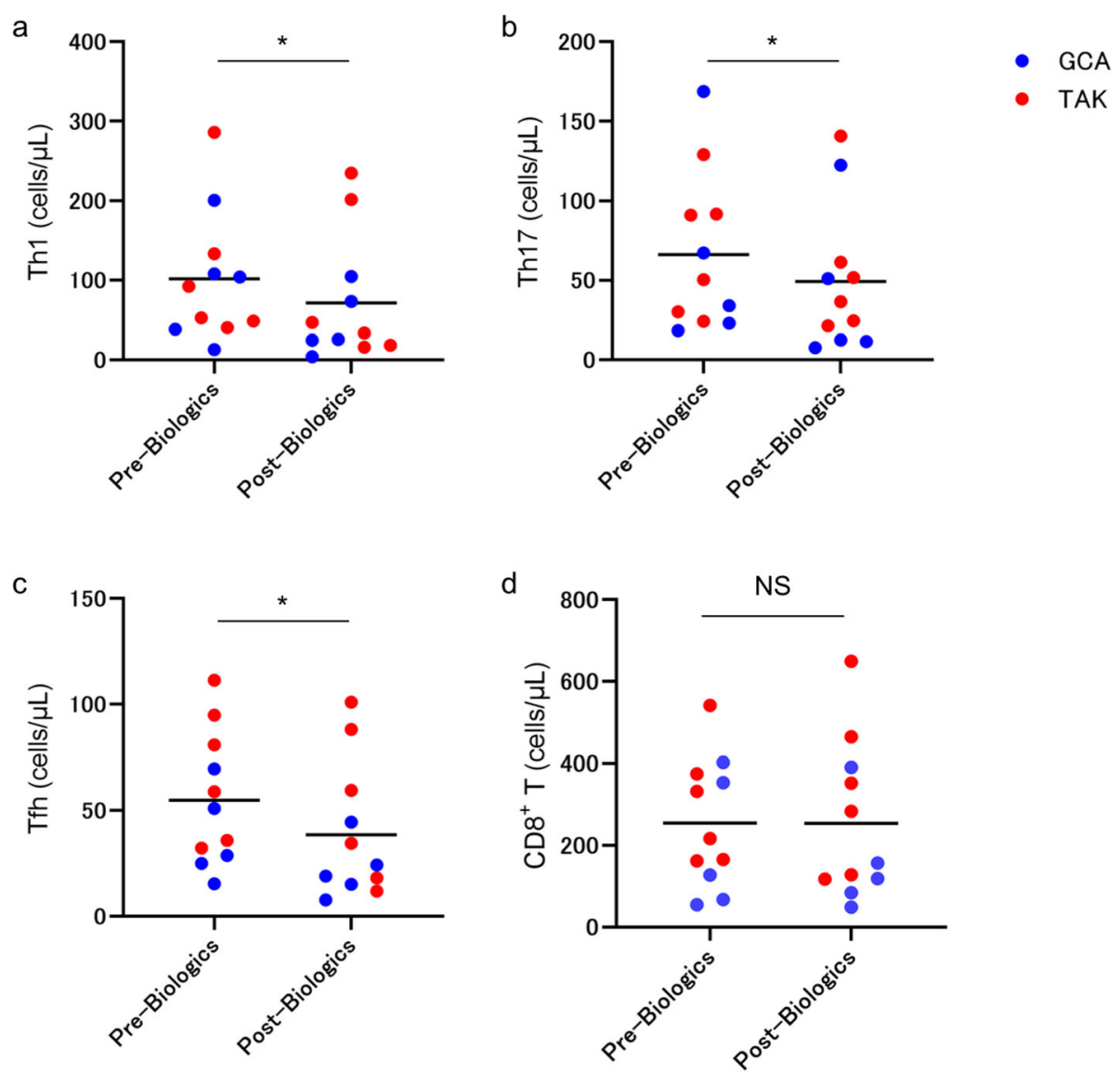

Fig. 4 The number of selected immune cell subsets before and after treatment with biologic agents. The number of a Th1, b Th17, c Tfh, and $\mathbf{d}$ $\mathrm{CD}^{+}$T cells before and after treatment with biologic agents in GCA $(n=5)$ and TAK $(n=6)$. Th, helper T; Tfh, follicular helper T; GCA, giant cell arteritis; TAK, Takayasu arteritis. ${ }^{*} p<0.05$ for Wilcoxon signed-rank test. NS, not significant

\section{Supplementary information}

Supplementary information accompanies this paper at https://doi.org/10. 1186/s13075-019-2068-7.

Additional file 1 : Figure $\mathbf{S 1}$ Immuno-phenotyping strategy using antibody staining.

Additional file 2: Figure S2 Heatmap of baseline and time-course immuno-phenotyping in patients successfully treated with GC and biologic agents. Fold change in each immuno-phenotype at baseline and at weeks 4, 12, 24 and 52 of treatment with GC and biologic agents in (A) GCA ( $n=5)$ and (B) TAK ( $n=3)$ patients without relapse. GC: glucocorticoid, GCA: giant cell arteritis, TAK: Takayasu arteritis.

Additional file $\mathbf{3}$ : Figure $\mathbf{S 3}$ Correlation analysis of disease activity with the number of immune cells in LW patients with relapse. Correlation coefficient for the number of each immune cells of each subset and disease activity in GCA $(n=4)$ and TAK $(n=3)$ patients with relapse. LW: large vessel vasculitis, GCA: giant cell arteritis, TAK: Takayasu arteritis.

Additional file $\mathbf{4}$ :Table S1. Antibodies used in FACS analysis. Table S2. Immuno-phenotyping strategy using antibody staining.

\section{Abbreviations}

CRP: C-reactive protein; CT: Computed tomography; ESR: Erythrocyte sedimentation rate; GC: Glucocorticoid; GCA: Giant cell arteritis; HCs: Healthy controls; HLA: Human leukocyte antigen; IBD: Inflammatory bowel disease; IFX: Infliximab; IL: Interleukin; LW: Large vessel vasculitis; MHC: Major histocompatibility; PMR: Polymyalgia rheumatica; PSL: Plednisolone; TAK: Takayasu arteritis; TCZ: Tocilizumab; Tfh: Follicular helper T; Th: Helper T; TNF: Tumor necrosis factor; Treg: Regulatory $T$

\section{Acknowledgements}

We are very grateful to Ms. Yumi Ikeda, Ms. Yuko Takaishi, and Ms. Kumiko Tanaka for their technical support.

\section{Authors' contributions}

$\mathrm{KM}, \mathrm{KS}, \mathrm{KY}$, and $\Pi$ designed the study. $\mathrm{KM}, \mathrm{KS}$, and $\Pi$ were involved in patient recruitment and data collection. All authors were involved in writing the manuscript and approved the final version. The corresponding author had full access to all of the data in the study and had final responsibility for the decision to submit the paper for publication.

\section{Funding}

This study was financially supported by the Mitsubishi Tanabe Pharma Corporation and Keio University School of Medicine.

\section{Availability of data and materials}

All data generated or analyzed during this study are included in this published article and its supplementary information files.

\section{Ethics approval and consent to participate}

This study was approved by the research ethics committee of the Keio University School of Medicine (\#20140335) and was conducted according to the Declaration of Helsinki. 


\section{Consent for publication}

Informed consent was obtained from all patients and HCs.

\section{Competing interests}

$\mathrm{KM}, \mathrm{KS}$, and $\mathrm{KY}$ declare that they have no competing interests. NS, HT, and KC were employees of Mitsubishi Tanabe Pharma Corporation. TT has received research grants from Mitsubishi Tanabe Pharma Corporation.

\section{Author details}

'Division of Rheumatology, Department of Internal Medicine, Keio University School of Medicine, 35 Shinanomachi, Shinjuku-ku, Tokyo, Japan. ${ }^{2} \mathrm{Clinical}$ and Translational Research Center, Keio University Hospital, 35 Shinanomachi, Shinjuku-ku, Tokyo, Japan. ${ }^{3}$ Mitsubishi Tanabe Pharma Corporation, 1000, Kamoshida-cho, Aoba-ku, Yokohama, Kanagawa, Japan.

Received: 4 September 2019 Accepted: 25 November 2019 Published online: 30 December 2019

\section{References}

1. Salvarani C, Cantini F, Hunder GG. Polymyalgia rheumatica and giant-cell arteritis. Lancet. 2008:372:234-45.

2. Gonzalez-Gay MA, Vazquez-Rodriguez TR, Lopez-Diaz MJ, Miranda-Filloy JA, Gonzalez-Juanatey C, Martin J, et al. Epidemiology of giant cell arteritis and polymyalgia rheumatica. Arthritis Rheum. 2009;61:1454-61.

3. Grayson PC, Maksimowicz-McKinnon K, Clark TM, Tomasson G, Cuthbertson D, Carette S, et al. Distribution of arterial lesions in Takayasu's arteritis and giant cell arteritis. Ann Rheum Dis. 2012;71:1329-34.

4. Jennette JC, Falk RJ, Bacon PA, Basu N, Cid MC, Ferrario F, et al. 2012 Revised International Chapel Hill Consensus Conference Nomenclature of Vasculitis. Arthritis Rheum. 2013;65:1-11.

5. Villiger PM, Adler S, Kuchen S, Wermelinger F, Dan D, Fiege $V$, et al. Tocilizumab for induction and maintenance of remission in giant cell arteritis: a phase 2, randomised, double-blind, placebo-controlled trial. Lancet. 2016:387:1921-7.

6. Stone $\mathrm{JH}$, Tuckwell K, Dimonaco S, Klearman M, Aringer M, Blockmans D, et al. Trial of tocilizumab in giant-cell arteritis. N Engl J Med. 2017; 377:317-28.

7. Nakaoka Y, Isobe M, Takei S, Tanaka Y, Ishii T, Yokota S, et al. Efficacy and safety of tocilizumab in patients with refractory Takayasu arteritis: results from a randomised, double-blind, placebo-controlled, phase 3 trial in Japan (the TAKT study). Ann Rheum Dis. 2018;77:348-54.

8. Molloy ES, Langford CA, Clark TM, Gota CE, Hoffman GS. Anti-tumour necrosis factor therapy in patients with refractory Takayasu arteritis: longterm follow-up. Ann Rheum Dis. 2008;67:1567-9.

9. Gudbrandsson B, Molberg $\varnothing$, Palm $\varnothing$. TNF inhibitors appear to inhibit disease progression and improve outcome in Takayasu arteritis; an observational, population-based time trend study. Arthritis Res Ther. 2017; 19:99.

10. Langford CA, Cuthbertson D, Ytterberg SR, Khalidi N, Monach PA, Carette S, et al. A randomized, double-blind trial of abatacept (CTLA-4lg) for the treatment of giant cell arteritis. Arthritis Rheumatol. 2017:69:837-45.

11. Hunder GG, Bloch DA, Michel BA, Stevens MB, Arend WP, Calabrese LH, et al. The American College of Rheumatology 1990 criteria for the classification of giant cell arteritis. Arthritis Rheum. 1990;33:1122-8.

12. Kermani TA, Warrington KJ, Cuthbertson D, Carette S, Hoffman GS, Khalidi NA, et al. Disease relapses among patients with giant cell arteritis: a prospective, longitudinal cohort study. J Rheumatol. 2015;42:1213-7.

13. Dasgupta B, Cimmino MA, Maradit-Kremers H, Schmidt WA, Schirmer M, Salvarani C, et al. 2012 provisional classification criteria for polymyalgia rheumatica: a European League Against Rheumatism/American College of Rheumatology collaborative initiative. Ann Rheum Dis. 2012;71:484-92.

14. Mowat C, Cole A, Windsor A, Ahmad T, Arnott I, Driscoll R, et al. Guidelines for the management of inflammatory bowel disease in adults. Gut. 2011;60: 571-607.

15. Maecker HT, McCoy JP, NUssenblatt R. Standardizing immunophenotyping for the Human Immunology Project. Nat Rev Immunol. 2012;12:191-200.

16. Furuta S, Cousins C, Chaudhry A, Jayne D. Clinical features and radiological findings in large vessel vasculitis: are Takayasu arteritis and giant cell arteritis 2 different diseases or a single entity? J Rheumatol. 2015:42:300-8.
17. Kermani TA, Crowson CS, Muratore F, Schmidt J, Matteson EL, Warrington KJ. Extra-cranial giant cell arteritis and Takayasu arteritis: how similar are they? Semin Arthritis Rheum. 2015;44:724-8.

18. Deng J, Younge BR, Olshen RA, Goronzy JJ, Weyand CM. Th17 and Th1 Tcell responses in giant cell arteritis. Circulation. 2010;121:906-15.

19. Saadoun D, Garrido M, Comarmond C, Desbois AC, Domont F, Savey L, et al. Th1 and Th17 cytokines drive inflammation in Takayasu arteritis. Arthritis Rheumatol. 2015;67:1353-60.

20. Kermani TA. Takayasu arteritis and giant cell arteritis: are they a spectrum of the same disease? Int J Rheum Dis. 2019;22(Supple 1):41-48.

21. Matsumoto K, Suzuki K, Yoshimoto K, Seki N, Tsujimoto H, Chiba K, et al. Significant association between clinical characteristics and immuno phenotypes in patients with ANCA-associated vasculitis. Rheumatology (OXFORD). 2019;doi:https://doi.org/10.1093/rheumatology/kez327.

22. Corbera-Bellalta M, Planas-Rigol E, Lozano E, Terrades-García N, Alba MA, Prieto-González S, et al. Blocking interferon $y$ reduces expression of chemokines CXCL9, CXCL10 and CXCL11 and decreases macrophage infiltration in ex vivo cultured arteries from patients with giant cell arteritis. Ann Rheum Dis. 2016;75:1177-86.

23. Terao C. Revisited HLA and non-HLA genetics of Takayasu arteritis--where are we? J Hum Genet. 2016;61:27-32.

24. Terao C, Yoshifuji H, Matsumura T, Naruse TK, Ishii T, Nakaoka Y, et al. Genetic determinants and an epistasis of LILRA3 and HLA-B*52 in Takayasu arteritis. Proc Natl Acad Sci U S A. 2018:115:13045-50.

25. Barrier J, Bignon JD, Soulillou JP, Grolleau J. Increased prevalence of HLADR4 in giant-cell arteritis. N Engl J Med. 1981:305:104-5.

26. Carmona FD, González-Gay MA, Martín J. Genetics component of giant cell arteritis. Rheumatology (Oxford). 2014:53:6-18.

27. Polachek A, Pauzner R, Levartovsky D, Rosen G, Nesher G, Breuer G, et al. The fine line between Takayasu arteritis and giant cell arteritis. Clin Rheumatol. 2015:34:721-7.

28. Miyabe C, Miyabe Y, Strle K, Kim ND, Stone JH, Luster AD, et al. An expanded population of pathogenic regulatory T-cells in giant cell arteritis is abrogated by IL-6 blockade therapy. Ann Rheum Dis. 2017;76:898-905.

\section{Publisher's Note}

Springer Nature remains neutral with regard to jurisdictional claims in published maps and institutional affiliations.

Ready to submit your research? Choose BMC and benefit from:

- fast, convenient online submission

- thorough peer review by experienced researchers in your field

- rapid publication on acceptance

- support for research data, including large and complex data types

- gold Open Access which fosters wider collaboration and increased citations

- maximum visibility for your research: over $100 \mathrm{M}$ website views per year

At BMC, research is always in progress.

Learn more biomedcentral.com/submissions 